\title{
URGENSI KOMUNIKASI EFEKTIF DALAM PROSES TRANSFER INFORMASI DI PERPUSTAKAAN PERGURUAN TINGGI
}

\author{
RORY RAMAYANTI \\ e_mail: roryramayanti@uinjambi.ac.id \\ ILMU PERPUSTAKAAN DAN INFORMASI ISLAM FAH UIN SULTHAN THAHA \\ SAIFUDDIN JAMBI
}

\begin{abstract}
This paper describes how the role of effective communication in speeding up the process of transfer of information in the College Library. There are three issues into the discussion in this paper; (i) effective communication in the process of transfer of information with assertive communication by considering personal rights between librarians and users; (ii) how to create effective communication between librarians with the user by means of the receiver understand the message conveyed, can establish a good relationship between librarians and users, the message shoving on a response desired message recipients; (iii) This paper outlines the third obstacle in conducting effective communication among them is a different background, signals, communication situation, quality of the content of the message, writing skills, speaking skills, the skills of listening, reading skills
\end{abstract}

Key word: effective communication, transfer of information, college library

\section{A. PENDAHULUAN}

Keberadaan perpustakaan merupakan salah satu faktor akselerasi transfer ilmu pengetahuan yang tidak dapat dipisahkan dari sistem pendidikan suatu lembaga. Dikutip dari Rosa \& Hoffman dalam Eberhart menyatakan bahwa survei yang dilakukan oleh ALA pada tahun 2009-2011 untuk mengetahui penilaian publik terhadap perpustakaan menunjukkan bahwa 95\% masyarakat Amerika setuju bahwa perpustakaan perguruan tinggi dan penelitian merupakan bagian yang sangat penting dari komunitas pembelajaran. 97\% masyarakat juga berpendapat bahwa perpustakaan perguruan tinggi dan penelitian menghubungkan antara pemustaka dengan dunia pengetahuan. ${ }^{1}$

Dalam kegiatan transfer ilmu pengetahuan dibutuhkan sebuah interaksi antara penyedia jasa pengetahuan dalam hal ini perpustakaan dengan pihak yang membutuhkan pengetahuan tersebut dalam hal ini pengguna. Komunikasi merupakan salah satu cara yang dapat dilakukan oleh pustakawan dalam berinteraksi dengan pengguna. Pustakawan harus memperhatikan cara berkomunikasi dengan penggunanya karena hal ini akan memperngaruhi kualitas pelayanan. Jika kualitas pelayanan buruk maka pengguna akan

${ }^{1}$ George M Eberhart, The Whole Library Handbook 5: Current data, professional advice, and Curiosa. (USA: Priority Publishing, 2013) Hal. 4 
enggan untuk menggunakan perpustakaan. Hal ini tentu saja akan menghambat proses transfer informasi di pepustakaan.

Salah satu aspek untuk menentukan kualitas layanan sebuah perpustakaan yang ideal adalah komunikasi yang efektif. Komunikasi yang efektif adalah komunikasi yang hasilnya sesuai dengan harapan para pesertanya (orang-orang yang berkomunikasi). ${ }^{2}$ Proses komunikasi efektif memungkinkan pemustaka untuk mendapatkan informasi sesuai dengan keinginannya atau bahkan lebih dari yang diharapkan. Kegiatan komunikasi efektif merupakan salah satu cara untuk mentransfer informasi agar semua sumber informasi yang ada di perpustakaan dapat dimanfaatkan semaksimal mungkin oleh pengguna. Tulisan ini mendeskripsikan pentingnya menciptakan komunikasi yang efektif dalam proses mentransfer informasi di perpustakaan perguruan tinggi

\section{B. KAJIAN TEORI}

1. Perpustakaan Perguruan Tinggi

Perpustakaan perguruan tinggi adalah perpustakaan yang terdapat pada perguruan tinggi, badan bawahannya, maupun lembaga yang berfaliasidengan perguruan tinggi, dengan tujuan utama membantu perguruan tinggi mencapai tujuannya. Tujuan perguruan tinggi di Indonesia dikenal dengan Tri Darma perguruan tinggi (pendidikan, penelitian, pengabdian masyarakat). ${ }^{3}$

Perpustakaan perguruan tinggi memiliki karekteristik yang sedikit berbeda dengan perpustakaan lainnya. Diperguruan tinggi keberadaan perpustakaan sangatlah penting. Karena perpustakaan merupakan sumber ilmu pengetahuan yang akan menunjang pembelajaran dan penelitian. Pustakawan pada perpustakaan perguruan harus memiliki kompetensi agar transfer informasi berjalan dengan baik.

Susan C. Curzon dalam Alire \& Evans menyatakan perpustakaan perguruan tinggi akan melanjutkan peran utamanya dalam membantu pemustaka menemukan informasi. Pesatnya perkambangan sumber informasi online bukan berarti mahasiswa memiliki perkembangan keterampilan yang sama dalam hal pencarian informasi. Dalam area pencarian informasi, pustakawan harus mempunyai 4 peran utama yaitu: ${ }^{4}$ a. Pustakawan menyaring informasi, membuat seleksi dari kesatuan sumber pengetahuan yang luas untuk menunjang pembelajaran

\footnotetext{
${ }^{2}$ Deddy Mulyadi. Ilmu Komunikasi: suatu pengantar. (Bandung: Remaja Rosda Karya, 2009) Hal. 117

${ }^{3}$ Sulistyo-Basuki. Pengantar Ilmu Perpustakaan. (Jakarta: Gramedia Pustaka Utama, 1991) Hal. 41

${ }^{4}$ Camila A Alire, \& G. Edward Evans.. Academic Libarianship. (USA: Neal-Schuman Piblisher, 2010)
} Hal. 347 
b. Pustakawan sebagai pengemudi, petunjuk pengguna satu per satu menuju pada sumber informasi

c. Pustakawan sebagai pendidik, mengajarkan mahasiswa keterampilan inti dari literasi informasi

d. Pustakawan sebagai penyebar informasi, menghubungkan secara asertif antara pengguna pada sumber informasi

Dari peran tersebut dapat dilihat bahwa pustakawan pada perpustakaan perguruan tinggi memiliki interaksi yang tinggi dengan pemustakanya. Agar peran tersebut berjalan dengan baik maka dibutuhkan komunikasi yang efektif dengan pemustaka.

2. Komunikasi Efektif Pustakawan

Komunikasi adalah interaksi dari unsur-unsur pengirim, penerima, pesan, saluran komunikasi, dan tujuan komunikasi. ${ }^{5}$ Komunikasi efektif adalah proses dimana informasi ditransmisikan dengan tepat dan dipahami oleh dua orang atau lebih. $^{6}$

Komunikasi efektif adalah sejauh mana komunikator mampu berorientasi kepada komunikannya. Berorientasi artinya melihat dan memahami tingkat akal budi (decorder dan interpreter) berikut peralatan jasmaniah (receiver) yang dimiliki komunikan; mengingat hal ini terkait dengan pemilihan pesan, makna pesan, struktur pesan dan cara penyajian pesan, termasuk pula penentuan saluran/media yang anda harus lakukan selaku komunikator. ${ }^{7}$

Berdasarkan pengertian diatas dapat disimpulkan bahwa komunikasi efektif adalah proses penyampaian pesan yang berorientasi pada komunikannya dengan tepat dan dapat dipahami.

Agar komunikasi berlangsung efektif harus memenuhi beberapa hal sebagai berikut: ${ }^{8}$

1. Penerima mengerti pesan yang disampaikan

2. Dapat mendirikan hubungan yang baik antara anda dan penerima pesan

3. Pesan tersebut mendorong pada sebuah tanggapan yang diinginkan penerima pesan

${ }^{5}$ Lasa HS, Kamus Kepustakawanan Indonesia. ( Yogyakarta: Pustaka Book Publisher, 2009) Hal. 178

${ }^{6}$ Elizabeth I Ifidon, \& Richard N.C. Ugwuanyi. "Effective Communication in Academic Libraries: an Imperative for Knowledge Delivery", (International Journal of Library anf Information Science, Vol: 5 No. : http://www.academicjournals.org/IJLIS) Akses pada: 08-08-2014

${ }^{7}$ Dani Vardiansyah, Pengantar Ilmu Komunikasi. (Bogor: Ghalia Indonesia, 2004) Hal.111 4

${ }^{8}$ Brantley \& Miller. Effective Communication for Colleges. (USA: Thomson South-Western, 2008) Hal. 
Persoalan utama dalam komunikasi efektif adalah sejauh mana motif komunikasi komunikator terwujud dalam diri komunikannya. Apabila motif komunikasi kita maknai sebagai tujuan komunikasi, maka dapat dinyatakan bahwa: (1) apabila hasil yang didapatkan sama dengan tujuan yang diharapkan, dikatakan bahwa komunikasi berlangsung efektif; (2) apabila hasil yang didapatkan lebih besar dari tujuan yang diharapkan, dikatakan bahwa komunikasi berlangsung sangat efektif. Sebaliknya, (3) apabila hasil yang didapatkan lebih kecil daripada tujuan yang diharapkan, dikatakan bahwa komunikasi tidak atau kurang efektif. Ketiga kondisi ini dapat ditulis secara matematis sebagai berikut ${ }^{9}$.

Tabel: kondisi komunikasi efektif

\begin{tabular}{|l|l|}
\hline \multicolumn{1}{|c|}{ Kondisi } & \multicolumn{1}{c|}{ Keterangan } \\
\hline $\mathrm{H}=\mathrm{T}$ & Komunikasi efektif \\
\hline $\mathrm{H}>\mathrm{T}$ & Komunikasi sangat efektif \\
\hline $\mathrm{H}<\mathrm{T}$ & Komunikasi kurang efektif \\
\hline
\end{tabular}

Beberapa aspek yang harus dipenuhi agar komunikasi pustakawan kepada pngguna berlangsung secara efektif adalah penuh pertolongan (helpful); tenggang rasa (considerate); empati (empathy); penuh perhatian (attentive); sopan (polite); peduli (respectfull); dapat didengarkan (audible); kejelasan (clarity); rasa percaya (trust); peduli (care); sikap rendah hati (humble/down to earth). ${ }^{10}$

\section{PEMBAHASAN}

\section{Komunikasi Efektif dalam Proses Transfer Infomasi}

Salah satu kompetensi personal yang harus dimiliki pustakawan menurut Libraries Association (SLA) yaitu keterampilan pustakawan dalam berkomunikasi. ${ }^{11}$ Jika dikaitkan dengan tugas pustakawan khususnya pada perpustakaan perguruan tinggi maka pustakawan harus memiliki keterampilan berkomunikasi dalam menyebarkan informasi, dan menghubungkan secara asertif antara pengguna ada sumber informasi.

Proses transfer pengetahuan harus dilakukan secara tepat dan dengan waktu yang tepat pada pada saat pengguna menginginkannya. Proses transfer pengetahuan dan informasi di perpustakaan perguruan tinggi dilakukan dengan berbagai pola - pola komunikasi yang meliputi komunikasi formal dan informal, elektronik, verbal dan non-

\footnotetext{
${ }^{9}$ Dani Vardiansyah, Pengantar Ilmu Komunikasi ... Hal. 10-11

${ }^{10}$ Fatmawati, Endang. The Art of Library: Ikatan Esai Bergizi tentang Seni Mengelola perpustaka. (Semarang: Badan Penerbit universtas Diponegoro Semarang, 2010) Hal. 183-184

${ }^{11}$ Sudarsono, Blasius. Antologi Kepustakawanan Indonesia. ( Jakarta: Ikatatan Pustakawan Indonesia, 2006) Hal. 151
} 
verbal dan tertulis. Jenis komunikasi tersebut diterapkan di perpustakaan perguruan tinggi sehingga komunikasi efektif terhadap transfer ilmu pengetahuan dapat berlangsung.

Secara umum, dalam ungkapan Fred E. Jandt yang dikutip dari Mulyana, komunikasi efektif idealnya dapat ${ }^{12}$ :

a. Meningkatkan keterampilan verbal dan nonverbal komunikasi. Komunikator efektif memiliki kemampuan untuk memilih dan menampilkan perilaku komunikasi yang layak untuk berbagai keadaan.

b. Mampu berkomunikasi efektif dalam situasi asing. Kita semua mengalami stres dalam situasi asing. Komunikator lebih efektif mengenali dan menangani stres tersebut.

c. Mengenali pengaruh yang ditimbulkan budaya sendiri atas cara pandang terhadap dirisendiri dan kurang terancam oleh orang-orang dengan latar belakang berbeda

d. Memperluas pengetahuan tentang budaya lain. Komunikator lebih efektif mengetahui banyak tentang norma dan nilai bdaya lain.

Untuk menjadi seorang komunikator yang efektif, kita harus berusaha menampilkan komunikasi (baik verbal ataupun nonverbal) yang disengaja seraya memahami budaya orang lain mungkin tidak disengaja, baik dalam arti di luar kesadarannya ataupun dalam arti ia tidak menggunakan pesan yang sesuai dengan budaya kita.

Seorang pustakawan yang baik harus menggunakan komunikasi efektif dalam berinteraksi dengan pengguna. Dalam hal ini pustakawan harus menguasai arti dari katakata dan simbol-simbol tertentu yang dibawakan oleh pengguna. Pustakawan juga harus mengetahui media komunikasi yang cocok untuk situasi tertentu.

Komunikasi yang efektif dapat mencipatakan suasana dan hubungan yang ramah antara pustakawan dan penggunanya. Pada saat mereka mengekspresikan perasaan dan pikiran, mereka akan dapat lebih mengenal satu sama lain, terbuka dan akrab. Komunikasi yang efektif harus diatu sedemikian rupa agar dapat meraih perhatian, cinta kasi, minat, kepedulian, simpati tanggapan, maupun respon positif dari pemustaka. ${ }^{13}$

Keberhasilan transfer informasi di perpustakaan perguruan tinggi juga harus memperhatikan komunikasi efektif karena layanan yang ditawarkan sangat bergantung pada komunikasi. Kegagalan dalam melakukan komunikasi akan memunculkan ketidakpuasan dan hilangnya kerjasama antara pustakawan dan pengguna, selain itu juga akan menyebabkan ketidak sesuaian.

\footnotetext{
${ }^{12}$ Deddy Mulyana, Komunikasi Efektif: Suatu Pendekatan Lintas Budaya. (Bandung: Remaja Rosdakarya, 2008). Hal. xviii

${ }^{13}$ Endang Fatmawati, The Art of Library ... Hal. 182
} 
Agar komunikasi yang dilakukan efektif, komunikan memahami dan melakukan sesuai dengan isi pesan yang diharapkan komunikator (pustakwan), lakukanlah komunikasi secara asertif. Maksud asertif disini adalah pustakawan berusaha untuk mendapatkan hak pribadi pustakawan dalam mendapatkan hak pribadi pustakawan dalam menyampaikan pesan, tanpa harus merampas hak pemustaka untuk bertanya lebih lanjut. Maka dari itu, pustakawan harus memberi waktu kepada penngguna untuk menanyakan lebih lanjut dari hal-hal yang belum jelas pada waktu pustakawan menelaskannya. Harapannya dengan perilaku asertif pustakawan ini adalah terjadinya komunikasi yang lebih efektif, karena ada keterlibatan emosi antara pustakawan dan pengguna.

2. Menciptakan Komunikasi Efektif antara Pustakawan dengan Pengguna

a. Penerima mengerti pesan yang disampaikan

Salah satu ukuran yang dapat digunakan sebagai ukuran komunikasi dikatakan efektif, adalah apabila makna pesan yang dikirim oleh komunikator sama dengan makna pesan yang diterima oleh komunikan (Suranto, 2011: 78)

Seorang pustakawan pada saat bekomunikasi dengan pemustaka, berposisi sebagai komunikator, sedangkan pemustaka menjadi komunikan. Komunikasi yang efektif akan terjadi bila pustakawan mampu menyelaraskan gaya komunikasinya dengan gaya komunikasi penggunanya.

Seringkali terjadi mis komunikasi yang disebabkan karena komunikan memahami makna pesan tidak sesuai dengan yang dimaksudkan oleh komunikator. Pada saat pustakawan menjelaskan cara penelusuran literatur tertentu, maka apabila pemustaka bisa mencari sesuai dengan yang dijelaskan pustakawan tersebut maka bisa dikatakan sudah efektif. Artinya komunikasi berhasil.

Ada beberapa hal yang harus diperhatikan ketika kita mengirim atau menerima pesan agar dapat dimengerti oleh orang lain adalah sebagai berikut (Martini, 2010: 6.28):

1) Buatlah pesan secara lengkap dan spesifik. Pernyataan harus jelas dan mencakup semua informasi yang diperlukan penerima untuk memahami pesan

2) Sesuaikan antara pesan verbal dan pesan non verbal

3) Kirimkan pesan lebih dari satu kali dengan menggunakan lebih dari 1 (satu) saluran komunikasi. Misalnya berbicara dan menuliskannya

4) Mintalah umpan balik agar kita dapat mengetahui apakah penerima benar-benar memahami pesan yang kita sampaikan

5) Dalam mengirimkan pesan, sesuaikan dengan kerangka pemikiran "si penerima". 
b. Dapat mendirikan hubungan yang baik antara anda dan penerima pesan

Komunikasi yang efektif dapat mendorng terjadinya hubungan positif antara pustakawan dan pemustaka. Dengan berkomunikasi secara efektif pustakawan dapat memiliki image yang baik di mata pemustaka. Terjadinya hubungan yang baik tersebut akan meningkatkan minat pemustaka untuk mengunjungi perpustakaan.

Misalnya ketika berada pada layanan referensi seorang pemustaka menanyakan mengenai sumber informasi apa saja yang tersedia di perpustakaan untuk keperluan risetnya. Dengan menggunakan bahasa verbal yang baik serta menunjukkan sikap non verbal yang baik pustakawan menuntun pemustaka menuju pada sumbersumber informasi yang ia butuhkan. Pemustaka akan merasa senang karena masalahnya dapat terselesaikan dan berkeinginan untuk kembali mengunjungi perustakaan tersebut.

Dalam hal ini pustakawan sebaiknya menjadi pendengar yang baik. Yaitu mendengarkan kebutuhan pemustakanya agar dapat memahami apa yang sebenarnya diinginkan oleh pemustaka. Adapun cara untuk melatih diri sebagai pendengar yang baik adalah sebagai berikut (Martini, 2010:6.28-6.29):

1) Mendengarkan itu untuk memahami, bukan menanggapi.

2) Jangan terlalu cepat menilai atau mengmbil kesimpulan. Sebaliknya simak perkataan lawan bicara dengan objektif.

3) Awasi pula pesan non verbal (bahasa tubuh) anda dan dia

4) Jangan mudah menyela pembicaraan, kecuali kalau ingin memberi dan meminta penjelasan

5) Sesekali ajukan pertanyaan agar kita dapat benar-benar memahami pesan yang disampaikan

6) Ulangi apa yang anda dengar sebagai umpan balik bagi sipengirim pesan sehingga ia tahu apakah penerima pesan memahami dengan benar

7) Jika kita mendengarkan orang yang bercerita untuk mengurangi beban batinnya, maka berikanlah dukungan dengan mendengarkan sungguh-sungguh sebelum merespon.

c. Pesan tersebut mendorong pada sebuah tanggapan yang diinginkan penerima pesan

Sebagai contoh, pada ketika pemustaka menanyakan lokasi sebuah buku, seringkali pustakawan hanya menunjuk ke arah rak buku. Tentu saja hal ini sangat membingungkan pemustaka yang tidak tahu buku tersebut berada pada rak bagian 
mana. Hal ini mengindikasikan bahwa pesan yang disampaikan oleh pustakawan tidak sesuai dengan yang diinginkan oleh pemustaka.

Pustakawan harus peka terhadap segala ekspresi yang di tunjukan oleh pemustaka. Ketika mendapati pustakawan yang merasa kebingungan, pustakawan harus menunjukan sikap empati terhadap pemustaka.

Agar pesan kita sesuai dengan tanggapan yang kita inginkan oleh pemustaka kita harus memperhatikan tingkah laku ketika berkomunikasi hal ini akan mengarahkan pada iklim Supportiveness. Seperti yang ditegaskan Gibb dalam Muhammad (2009: 85-86) tingkah laku tersebut meliputi:

1) Deskripsi, pustakawan harus memfokuskan pesan mereka kepada kejadian yang dapat diamati daripada evaluasi secara subjektif atau emosional

2) Orientasi masalah, pustakawan memfokuskan komunikasi mereka kepada pemecahan kesulitan mereka secara bersama-sama

3) Spontanitas, anggota organisasi berkomunikasi dengan sopan dalam merespons terhadap situasi yang terjadi

4) Emphati, memperlihakan perhatian dan pengertian terhadap anggota lainnya

5) Kesamaan, memperlakukan orang lain sacara sama, tidak membedakan kedudukan dan status sosial seseorang

6) Profesionalism, anggota organisasi bersifat fleksibel dan menyesuaikan diri pada situasi komunikasi yang berbeda-beda.

3. Hambatan Komunikasi Efektif

Brantley \& Miller ada beberapa hal yang memungkinkan menjadi hambatan dari komunikasi efektif yang akan di uraikan sebagai berikut ${ }^{14}$ :

a. Latar belakang yang Berbeda

Berbedaan budaya menyiratkan adanya percampuran bahasa, nilai, kepercayaan, adat istiadat agama dan pendidikan.banyak negara yang memiliki budaya nasional yang berbeda dari tiap kelompok populasi.

Berbedaan latar belakang budaya dana menjadi dampak yang signifikan bagi audiens untuk mengerti sebuah pesan. Latar belakang budaya mencakup pengaruh etnik dan geografis. Pengaruh etnik merupakan refleksi dari originalitas nasional. Pengaruh geografis merupakan refleksi seperti faktor populasi, kepadatan penduduk,

${ }^{14}$ Brantley \& Miller. Effective Communication for Colleges. (USA: Thomson South-Western, 2008) Hal. 
industrialisasi, dan iklim. Agar komunikasi dapat berlangsung efektif, kita harus memahami petunjuk dan memahami tips berkomunikasi untuk daerah khusus.

b. Sinyal

Sinyal pada waktu melakukan komunikasi nonverbal mengacu pada pesan yang disampaikan tanpa kata-kata. Sinyal mencakup nada intonasi suara dan bahasa tubuh (ekspresi wajah, isyarat, dan bentuk fisik yang lain). Cara berjalan, berdiri, dan gaya kepala yang mengartikan sesuatu. Setiap negara memiliki isyarat yang berbeda dalam mengkomunikasikan sesuatu.

c. Situasi Komunikasi

Situasi koumunikasi berpengaruh pada cara merumuskan dan mentransmisikan pesan. Sebagai contohnya, bentuk pesan dalam komunikasi formal akan berbeda dengan pesan komunikasi informal.

d. Kualitas Isi Pesan

Ketika isi pesan yang diterima kacau, maka akan terjadi miskomunikasi. Pesan yang efektif mencakup 6 (enam) kualitas untuk membantu pengirim dan penerima menjangkau sebuah pemahaman yang bermutu.

a. Kehormatan: menulis pesan untuk merefleksikan sudut pandang penerima dan tepat pada kebutuhan penerima pesan

b. Kejelasan: menggunakan kosa kata yang sesuai dan variasi struktur, panjang, dan penempatan kalimat

c. Konsistensi: mengeliminasi kata yang tidak dibutuhkan

d. Sistematis: membangun gambaran untuk penerima pesan sampai kepada kata yang spesifik

e. Ketepatan: menggunakan referensi untuk mengeliminasi beberapa gangguan umum dari komunikasi. Memverifikasi akurasi dari informasi pesan, tatabahasa, ejaan, tanda baca. Membuat ketentuan terhadap penampilan secara kese,uruhan dari pesan yang diberikan akan membuat pesan menjadi lebih berkesan.

e. Keterampilan Menulis

Beberapa pesan yang diterima menimbulkan kesan yang abadi dari pembagian tugas yang berdasarkan kualitas pesan. Penerima memerlukan perhatian adanya kemungkinan pesan eror, format pesan yang tidak sesuai, atau tampilan pesan melebihi isi pesan. Penerima pesan bisa berasumsi organisasi anda atau anda tidak berkompeten. Hasilnya, tidak ada respon dari penerima pesan dan kita tidak tahu kenapa hal tersebut bisa terjadi. Keterampilan menulis yang baik meningkatkan kemungkinan respon yang positif. 
f. Keterampilan Berbicara

Saat ini, komunikasi bisa dibicarakan melalui telpon atau perorangan. Pesan yang strategis dan berkualitas di dalam sebuah teks akan terpenuhi oleh dua hal yaitu, percakapan dan penulisan pesan. Ketika kita mempunyai kompleksitas atau sensitivitas dalam membicarakan pesan untuk mentransmisikan, berjati-hati dalam merencanakan isi pesan. Kemudian penulisan isi pesan dan mempraktekkan apa yang dibicarakan di dalam pesan. Kita akan menjadi lebih terjamin dan efektif ketika menyelesaikan pembicaraan pesan

g. Keterampilan Mendengar

Mendengar merupakan salah satu yang sangat penting, tetapi sedikit sekali di praktekkan dilapangan. Keterampilan mendengar yang sedikit menyela proses komunikasi, mencegah penerima dari pemahaman yang benar pada isi pesan dari pengirim pesan.

h. Keterampilan Membaca

Sebagian besar pekerjaan menyediakan kesediaan untuk membaca, memahami, mengevaluasi memorandum, surat, format, dan laporan. Membaca untuk pengertian (pemahaman) adalah proses menentukan arti dari pesan.

Keterampilan membaca yang rendah menyela proses komunikasi, mencegah penerima memahami pesan secara benar. Keterampilan membaca yang tidak memadai bisa menyebabkan penerima pesan mampunyai masalah terhadap pengkodean kosa kata atau struktur kalimat yang di gunakan di dalam pesan. Hasilnya, penerima pesan salah menafsirkan niat pengirim pesan atau salah memahami isi pesan.

\section{KESIMPULAN}

Komunikasi merupakan salah satu kompetensi personal yang harus dimiliki oleh pustakawan. Komunikasi efektif merupakan salah satu cara untuk memperoses transfer pengetahuan secara tepat dan dalam waktu yang tepat. Beberapa cara untuk melakukan komunikasi efektif yaitu, penerima mengerti pesan yang disampaikan, dapat mendirikan hubungan yang baik antara anda dan penerima pesan, pesan tersebut mendorong pada sebuah tanggapan yang diinginkan penerima pesan. Dalam usaha menciptakankomunikasi yang efektif terdapat beberapa hambatan yang mungkin terjadi dilapangan yaitu, latar belakang yang berbeda, sinyal, situasi komunikasi, kualitas isi pesan, keterampilan menulis, keterampilan berbicara, keterampilan mendengar, keterampilan membaca 


\section{DAFTAR PUSTAKA}

Alire, Camila A. \& G. Edward Evans.. Academic Libarianship. USA: Neal-Schuman Piblisher, 2010

Brantley \& Miller. Effective Communication for Colleges. USA: Thomson South-Western, 2008

Brantley \& Miller. Effective Communication for Colleges. USA: Thomson South-Western, 2008

Eberhart, George M. The Whole Library Handbook 5: Current data, professional advice, and Curiosa. USA: Priority Publishing, 2013

Endang Fatmawati, The Art of Library: Ikatan Esai Bergizi tentang Seni Mengelola perpustaka. Semarang: Badan Penerbit universtas Diponegoro Semarang, 2010

Fatmawati, Endang. The Art of Library: Ikatan Esai Bergizi tentang Seni Mengelola perpustaka. Semarang: Badan Penerbit universtas Diponegoro Semarang, 2010

Ifidon, Elizabeth I \& Richard N.C. Ugwuanyi. "Effective Communication in Academic Libraries: an Imperative for Knowledge Delivery”, (International Journal of Library anf Information Science, Vol: 5 No. : http://www.academicjournals.org/IJLIS) Akses pada: 08-08-2014

Lasa, HS. Kamus Kepustakawanan Indonesia. Yogyakarta: Pustaka Book Publisher, 2009

Mulyadi, Deddy, Ilmu Komunikasi: suatu pengantar. (Bandung: Remaja Rosda Karya, 2009

Mulyana, Deddy. Komunikasi Efektif: Suatu Pendekatan Lintas Budaya. Bandung: Remaja Rosdakarya, 2008

Sudarsono, Blasius. Antologi Kepustakawanan Indonesia. Jakarta: Ikatatan Pustakawan Indonesia, 2006

Sulistyo-Basuki, Pengantar Ilmu Perpustakaan. Jakarta: Gramedia Pustaka Utama, 1991

Vardiansyah, Dani. Pengantar Ilmu Komunikasi. Bogor: Ghalia Indonesia, 2004 
Vol. 1 No. 1 2018/1440 